\title{
EVALUATION OF MOBILE DENTAL APPLICATIONS USING USER VERSION MOBILE APP RATING SCALE (UMARS)
}

\author{
Dr.Parvathy Thampy. P.S, Dr.Nijesh. J. E, Dr.Preetha Elizabeth Chaly, Dr.Shyam. S, \\ Dr.Vaishnavi.S. \\ Department of Public Health Dentistry, \\ Faculty of Dentistry, Meenakshi Academy of Higher Education and Research Institute, Chennai, Tamil Nadu, \\ India.
}

\begin{abstract}
To access \& cite this article

Website: jidam.idamadras.com

PURPOSE: The use of mobile phone applications (Apps) has the potential to revolutionize the conventional practice of dentistry. There is a remarkable proliferation of mobile health apps in the field of dentistry which necessitates an urgent and reliable evaluation of the quality of these apps. The main objective of the article is to analyze the quality of dental apps using a reliable tool.
\end{abstract}

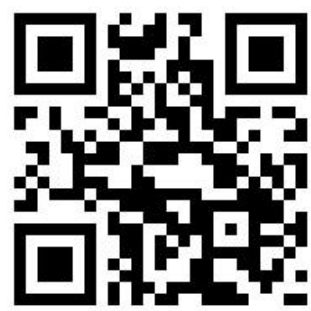

DOI:10.37841/jidam_2020_v7_i1_02

\section{Address for correspondence:}

Dr Nijesh. J. E., MDS.,

Assoc Professor, Department of Public Health Dentistry

Meenakshi Ammal Dental College and Hospital, Chennai

Email id: dr.j.e.nijesh@gmail.com

Received - 17.01.2020

Accepted - 18.02.2020

Published - 27.03.2020
METHOD: A systematic search was conducted on SamsungJ7 Prime and iPhone 7 using Google Play Store and App store respectively from June to August 2017 using the search terms "oral hygiene", "tooth brushing", oral health education", "baby teeth care". After due application of a predetermined selection criteria, twenty dental apps were randomly selected using computer software (www.randomizer.com). Each app was individually assessed and rated (1- inadequate, 2- poor, 3- acceptable, 4- good, 5excellent) according to a prevalidated user version of Mobile App Rating Scale (uMARS).

RESULT: The rating of dental apps used in this study ranged from $1.08 / 5$ to $3.25 / 5$. According to the objective criteria of uMARS, apps such as Brush DJ and Brush Up were found acceptable. Teeth Care Tips, Dental Surgery Simulator, Dental Expert and UC Dental were scored acceptable along with the former two apps under subjective criteria.

CONCLUSION: No apps scored good or excellent as per the uMARS criteria. As advances in technology have promoted the use of smart devices in health promotion and practices medical or dental apps must not only be informative and entertaining but also be evidence based and scientifically rated.

KEYWORDS: mHealth, Smartphones, Oral health, Mobile application, rating. 


\section{INTRODUCTION}

A mobile medical or dental app is a software application used on a mobile device for medical, dental or other health-related purposes. The wireless technology usage to deliver health services and information on mobile communication devices such as mobile phones, personal digital assistants, smartphones, monitoring devices, e-book readers, iPod and smart watches is known by the term mobile health or m-health. ${ }^{1}$ Mobile phones are an attractive platform for delivering remote patient monitoring services. ${ }^{2}$ In recent years, many researchers have employed mobile phones as tools for monitoring symptoms in heart diseases, diabetes and other chronic diseases. ${ }^{3}$ Smartphone ownership and internet usage continues to climb in emerging economies. According to PwC's Global Entertainment and Media Outlook 2019-2023, the number of smartphones in India has risen by more than $280 \%$ in the past five years, to $600 \mathrm{mn}$ in $2018 .^{4}$

mHealth is one of the largest sectors within Digital Health Care in India, with an estimated market size of 2,083 crore INR in 2015 which is set to rise to 5,184 crore INR by $2020 .^{5}$ Patients today are more conscious, tech-savvy and more willing to embrace emerging technologies. ${ }^{6}$ For ease of access and cost savings, the Indian population is readily adopting technology such as virtual medicine and health services apps due to high mobile penetration and a heavy share of the healthcare costs. There are now over 318,000 health apps available on the top app stores worldwide, nearly double the number of apps available in 2015 - with more than 200 apps being added each day. ${ }^{7}$ The top two categories among them are wellness management and disease management apps like diabetes, asthma, cardiac rehabilitation and pulmonary rehabilitation. The global mHealth app market is projected to be valued at US\$28.320 billion in 2018 and is expected to reach up to US\$102.35 billion by $2023^{7}$. The major driving factors fueling growth of the mHealth market is the increased adoption of smartphones, as well as the continued heavy investment into the digital health market. People desire more control of their health and are open to new ways of receiving care. However, the accuracy of the health information contained in most of these apps is not scrutinized by regulatory bodies, which could compromise user's health and safety.

According to the Global Burden of Disease study done between 1990 and 2010 focusing on 291 conditions, 3.9 billion people worldwide were affected with oral diseases. Untreated caries in permanent teeth affected $35 \%$ of the population whereas severe periodontal diseases, untreated caries in primary teeth and severe tooth loss affected $11 \%, 9 \%$ and $22 \%$ of global population respectively. ${ }^{8}$ Lack of perceived oral health needs among public is a major barrier to oral health care. A cross sectional qualitative research have shown that mobile applications are a promising tool to motivate an evidence based oral hygiene routine. ${ }^{9}$ Due to rapid proliferation of smartphone apps, it is difficult for end users to identify and access the right health apps. Little information is available beyond the star ratings which are published on the retailer web page. The star rating ranges from one to five, with one star denoting extreme dissatisfaction with an app and five stars denoting high satisfaction. The review comments and star ratings are the factors on which the downloads of an app are based. This rating reflects only the experience of the user with the app and is inconsistent. ${ }^{10}$

There is no scientific study conducted to assess the quality of the dental apps available. As a result, a sincere effort was made to evaluate the quality of existing mobile dental health apps using a pre validated tool - user version of Mobile App Rating Scale which is reliable for assessing the quality of mobile health apps

\section{METHODOLOGY}

A cross sectional study was initiated in the Department of Public Health Dentistry, for which a comprehensive App search was conducted in June 2017 with a completed updated search in August 2017, using Google Play store (SamsungJ7 Prime) and Appstore (iPhone 7). The search terms "oral hygiene", "tooth brushing", oral health education", "baby teeth care" was used. All freely downloadable, English language apps were included in the study. Purely gaming, exam oriented, dental specialty apps, dental products marketing and private clinic apps were excluded from the sampling frame (Fig 1). Of the remaining 98 apps, twenty dental apps were randomly selected by a computer software. (www.randomizer.org).

FIGURE 1: Flow diagram of the study search outline

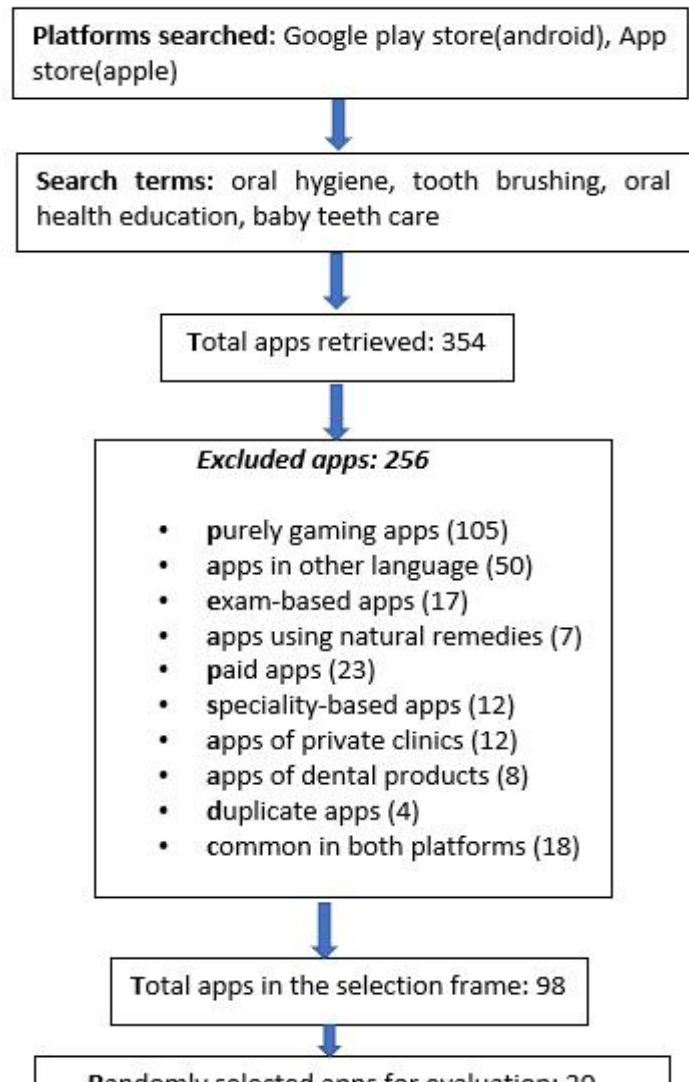

Randomly selected apps for evaluation: 20 
Figure 2. Screenshots of graded apps. A. My Dental Care. B. UC Dental. C. Brush Teeth

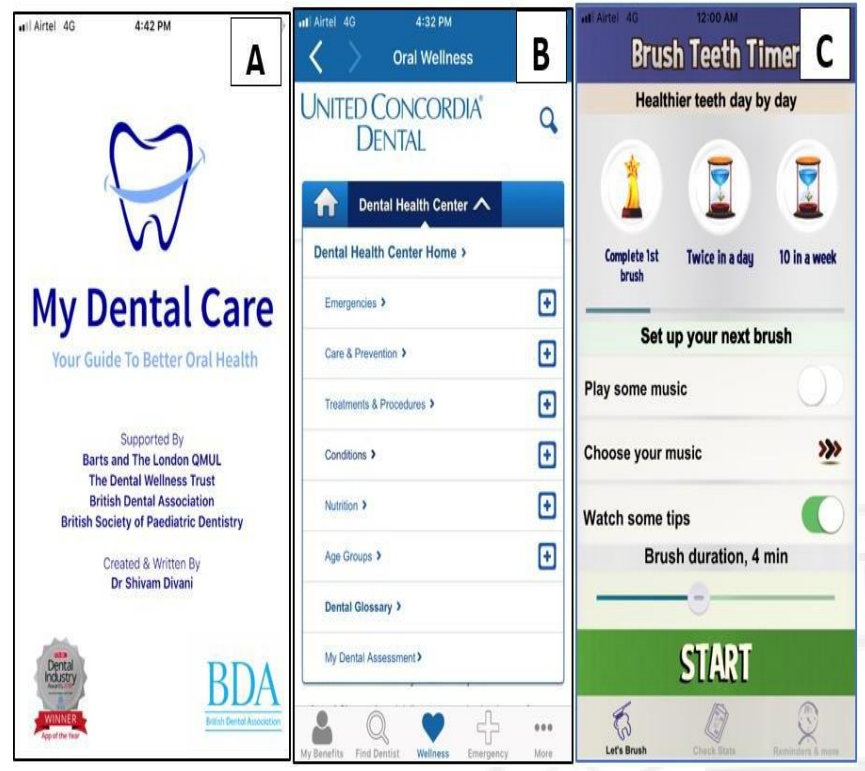

The selected apps were downloaded and installed in the appropriate mobile device (Fig 2). The selected apps were subjected to trial five times in a span of 2 weeks and were individually assessed and rated in isolation by the authors. Grading was performed independently by the principal investigator according to the user version of Mobile App Rating Scale. ${ }^{11}$ The star ratings and the number of downloads given in the publishers' web page were also recorded.

\section{Mobile App Rating Scale (MARS)}

Mobile App Rating Scale (MARS) is an evidence based mHealth app quality rating tool developed by Stoyan et al in 2014. ${ }^{12}$ Pretraining along with a substantial amount of expertise in the field of mHealth is required to use it correctly. Thus, the MARS has been simplified and modified for end users (UMARS), to be used as a reliable tool to assess and report the quality of mHealth apps. uMARS rates the quality of the mobile app both objectively and subjectively separately using 20 subcategories. ${ }^{11}$ The objective criteria measurement includes the Engagement, Functionality, Aesthetics and Information quality of the mobile app and each item is scored on a 5-point scale (1- inadequate, 2- poor, 3- acceptable, 4- good, 5- excellent). Mean scores instead of total scores are used because an item can be rated as Not applicable also. Additionally, mean scores are used for comparing with corresponding star ratings. Objective Quality Mean Score of the mobile app is obtained by summing up the mean scores of Engagement, Functionality, Aesthetics and Information quality subscales. Subjective Quality Mean Score is obtained by taking the mean of the scores obtained for four questions under subjective criteria (Would you recommend this app to people who might benefit from it?, How many times do you think you would use this app in the next 12 months if it was relevant to you?, Would you pay for this app?, What is your overall star rating of the app?).

\section{RESULTS}

A total of 354 dental apps were identified from android (Samsung J7 Prime) and iOS (iphone7) platform of which eighteen apps were common to both the platforms. A total of ninety- eight apps (Fifty-five apps from google play store and forty-three apps from app store) were identified using the selection criteria (Figure 2).

Apps like Dentist Office, Brush'n'Save, Dental Surgery Stimulator, Dental Care, Tooth Brush Timer, Brushy time, Easy Teeth Care tips and Quick Brush-Tooth brush timer were downloaded from Google play store. Teeth care tips, Text 2 Floss, Dental Expert, Brushing app and Brush teeth were retrieved from apple platform. A few apps like Brush DJ, Brush Up, Magic Timer, My Bright Smile, UC Dental, Family dental care, My Dental Care were present on both the platforms. The size of the apps ranged from 2.7 to 317.9 MB. Only freely downloadable apps were considered. Mean scores were calculated and tabulated after the authors scored the apps for objective subscales by applying the uMARS.

On analyzing the results none of the apps were scored good or excellent according to uMARS criteria. The UMARS objective scores ranged from $1.08 / 5$ to $3.25 / 5$. Brush DJ and Brush Up scored acceptable (3-4), thirteen of them scored poor (2-3) and remaining five apps scored were inadequate according to uMARS (Table 1). Only three out of the twelve apps star rating, matched with the subjective scores which shows its subjective nature. Moreover, the star ratings given in the web page are not reliable as they come from unknown source. 
Table 1: Table depicts the uMARS subjective and objective mean score and star ratings of dental apps:

\begin{tabular}{|c|c|c|c|c|c|c|c|c|}
\hline \multirow[t]{2}{*}{ App Name } & \multirow[t]{2}{*}{ Developer } & \multirow{2}{*}{$\begin{array}{c}\text { Star } \\
\text { rating }\end{array}$} & \multirow{2}{*}{$\begin{array}{c}\text { Subjective } \\
\text { Score }\end{array}$} & \multicolumn{5}{|c|}{ Objective score } \\
\hline & & & & Engagement & Functionality & Aesthetics & $\begin{array}{c}\text { Information } \\
\text { Quality }\end{array}$ & $\begin{array}{l}\text { Mean } \\
\text { score }\end{array}$ \\
\hline Brush DJ & $\begin{array}{l}\text { Ben } \\
\text { Underwood }\end{array}$ & 4.1 & 3.5 & 0.72 & 0.95 & 0.66 & 0.92 & 3.25 \\
\hline Brush Up & $\begin{array}{l}\text { Big Fun } \\
\text { Development }\end{array}$ & 3.6 & 3.25 & 0.84 & 0.6 & 0.8 & 0.85 & 3.09 \\
\hline $\begin{array}{l}\text { Dentist } \\
\text { Office }\end{array}$ & $\begin{array}{l}\text { Beansprites } \\
\text { LLC }\end{array}$ & 5 & 2.5 & 0.44 & 1 & 0.73 & 0.72 & 2.89 \\
\hline $\begin{array}{l}\text { Magic } \\
\text { Timer }\end{array}$ & Walt Disney & 3.9 & 2.5 & 0.6 & 0.75 & 0.87 & 0.64 & 2.86 \\
\hline $\begin{array}{l}\text { My bright } \\
\text { Smile }\end{array}$ & Colgate & 3.8 & 3.25 & 0.52 & 0.9 & 0.6 & 0.67 & 2.68 \\
\hline $\begin{array}{l}\text { Teeth care } \\
\text { tips }\end{array}$ & Rajesh Kumar & & 3.25 & 0.44 & 0.9 & 0.67 & 0.65 & 2.66 \\
\hline UC Dental & $\begin{array}{l}\text { Dental } \\
\text { Insurance Co }\end{array}$ & 3.3 & 3 & 0.68 & 0.75 & 0.47 & 0.75 & 2.65 \\
\hline $\begin{array}{l}\text { Dentist } \\
\text { Kids }\end{array}$ & & 3.2 & 2 & 0.64 & 0.7 & 0.6 & 0.65 & 2.59 \\
\hline $\begin{array}{l}\text { Dental } \\
\text { Surgery } \\
\text { Stimulator }\end{array}$ & Zain Zafar & 3.3 & 3.25 & 0.52 & 0.65 & 0.8 & 0.55 & 2.52 \\
\hline Text 2 Floss & $\begin{array}{l}\text { Arizona } \\
\text { School of } \\
\text { Dentistry and } \\
\text { Oral health }\end{array}$ & - & 2 & 0.44 & 0.75 & 0.53 & 0.7 & 2.42 \\
\hline $\begin{array}{l}\text { Family } \\
\text { dental care }\end{array}$ & $\begin{array}{l}\text { Dr Damyokef } \\
\text { Belote }\end{array}$ & - & 2 & 0.56 & 0.75 & 0.4 & 0.56 & 2.27 \\
\hline $\begin{array}{l}\text { My Dental } \\
\text { Care }\end{array}$ & $\begin{array}{l}\text { Dr Shivam } \\
\text { Divani }\end{array}$ & 5 & 2.75 & 0.28 & 0.75 & 0.4 & 0.8 & 2.23 \\
\hline Dental Care & $\begin{array}{l}\text { MSPLD } \\
\text { Developers }\end{array}$ & 4.6 & 2 & 0.6 & 0.5 & 0.6 & 0.52 & 2.22 \\
\hline $\begin{array}{l}\text { Dental } \\
\text { Expert }\end{array}$ & Marc Lazare & - & 3.5 & 0.4 & 0.65 & 0.4 & 0.75 & 2.2 \\
\hline
\end{tabular}




\begin{tabular}{|l|l|l|l|l|l|l|l|l|}
\hline $\begin{array}{l}\text { Brushing } \\
\text { app }\end{array}$ & Singer Dental & - & 1.5 & 0.36 & 0.8 & 0.33 & 0.66 & 2.15 \\
\hline Brush teeth & $\begin{array}{l}\text { Spyridon } \\
\text { Bousis }\end{array}$ & - & 1.25 & 0.56 & 0.35 & 0.27 & 0.33 & 1.51 \\
\hline $\begin{array}{l}\text { Tooth } \\
\text { Brush } \\
\text { Timer }\end{array}$ & Japps Medical & 4.2 & 1 & 0.36 & 0.25 & 0.4 & 0.45 & 1.46 \\
\hline Brushy time & Laser Boy & - & 1.25 & 0.36 & 0.3 & 0.4 & 0.35 & 1.41 \\
\hline $\begin{array}{l}\text { Easy Teeth } \\
\text { Care tips }\end{array}$ & Dierre09 & 2.7 & 1.25 & 0.28 & 0.45 & 0.25 & 0.35 & 1.33 \\
\hline $\begin{array}{l}\text { Quick } \\
\text { Brush- } \\
\begin{array}{l}\text { Toothbrush } \\
\text { timer }\end{array}\end{array}$ & $\begin{array}{l}\text { Samy } \\
\text { Nakayam }\end{array}$ & 3.5 & 1.25 & 0.28 & 0.39 & 0.2 & 0.3 & \\
\hline
\end{tabular}

\section{DISCUSSION}

Despite great improvements in oral health globally, problems still remain in many countries all over the world. This can be due to inequitable distribution of oral health care services. Technology now exists to support distance collaboration between dentists and the population. Electronic collaborations are frequently used in medicine but have only been slowly adopted in dentistry. Advances in technology have promoted the use of smart devices in health promotion and practices. Patients and the family care givers use different patterns of information seeking like internet or free mobile apps. Study done by Morwenna Kirwan et al showed that an app with much higher usability, might increase usage and maintenance of health behavior change in the long term. ${ }^{12}$ Due to this behavior, the efficiency of these must be evaluated randomly and the general public need to be forewarned to exercise caution when using health apps in general.

All the available dental apps were scrutinized using the search terms in two most popular app platforms from June -August 2017 for this study. Three hundred fifty-four dental apps have been retrieved. Applying the elimination criteria, the apps were further reduced to ninety-eight apps. Of which twenty apps were randomly selected and tested for proper functioning. The objective and subjective quality of these apps were assessed according to uMARS and then compared with their star ratings in the web page. The concurrent uMARS rating of the app when compared with star rating given in the web page did not match which is in line with the study conducted by Stoyan et al (2014) using MARS on mental health apps. ${ }^{13}$ Five-star ratings can be misleading as the vast majority of the users will be the one who always provide a positive rating as they were using it over competitive alternatives and want to justify their decision ${ }^{1}$. Very few in the population who had rated the apps would have been one-time users who have conducted an unbiased assessment of the available alternatives.

Brush DJ and Brush Up were scored acceptable (3-4). Thirteen of them scored poor (2-3) which is in line with the study conducted by Tiffany B et al in 2018 on oral health. ${ }^{14}$ Rest of the five apps were scored as inadequate according to uMARS. None of the apps rated Good or excellent according to uMARS. The number of available dental apps clearly expressed the interest of the public in experimenting with newer technologies in the field of oral health.

Given the recent development of mHealth apps, formal literature citing the efficacy of these apps remains limited. This is the first study attempted to evaluate the efficiency of dental apps scientifically. Most of the apps are self-explanatory and do not require trained personnel for its use. Although the reviews are performed on the App store not all the apps are supported or verified by an international verification board prior to the design or marketing. Only two national health authorities have issued specific guidance for mHealth apps; the UK National Health Service (NHS) and the French Haute Autorite de Santé (HAS) ${ }^{15}$.

Brush DJ app had evidence-based reference and previous baseline studies, which all serve to enhance its credibility. ${ }^{9}$ Brush Up developed by Big Fun Development is a Tooth Brush Training game and was titled "App of The Year" by National Academy of medicine and this app demonstrated to improve kids brushing in a National Institute of Health funded study.

Few apps like UC Dental, Family dental Care apps are customizable as it will help the individuals to use according to their requirements. Magic Timer, Brushy Time, 
Dental Care, Dental Surgery Stimulator were interesting to use and provide entertainment which add on to the Engagement criteria of the app. The performance, ease of use and navigation is perfect for some of the apps like Brush DJ, My Dental Care, Text 2 floss apps which add on to Functionality criteria of a good app. The Graphics, layout and visual appeal were good in My Bright Smile, Dentist Office which added to Aesthetics part. Teeth Care Tips, Text 2 floss, My Dental Care, UC Dental apps contain high quality information with references from credible source like American Dental Association, American Dental Hygienists Association, The Centres for Disease Control and Prevention, National Institute of Health, World Health Organization which will add on to the information criteria of the app quality. This is contradictory to the study conducted previously by Singh P in 2013 on orthodontic apps. ${ }^{16}$

Some features like Emergency steps was present in UC Dental app which can guide the patient in any dental causalities. Studies conducted by Al Musawi et al in 2017 showed that apps are an effective means of providing knowledge and guiding lay people in managing tooth avulsion, and it can be superior to a lecture-based delivery of information. ${ }^{17}$ Reminders to floss the teeth can be send by Text 2 floss app which helps to reinforce the flossing habit in patients. The ADA recommends brushing twice a day and cleaning between teeth with floss (or another interdental cleaner) once a day. ${ }^{18}$

Private clinics apps were also available in the app store which were not included in this study. Apps developed by the Lin CY et al in 2014 remind patients about every scheduled appointment, and help them take pictures of their own oral cavity parts. Dentists could confirm or change appointments easily and provide professional advice to their patients immediately taking advantage of cloud-based services. ${ }^{19}$

There can be a time discrepancy between the literature search, first submission and publication date and is ever so relevant in today's technological era and thus implies that the reviewed apps (within this study ) may be updated and newer apps may be available during the time of peer review process or any delays associated with eventual publication of this manuscript.

\section{RECOMMENDATIONS}

Despite the rapid expansion of mHealth apps, there are still significant barriers to expanding the role and efficacy of mHealth apps in improving the health of consumers due to lack of regulatory supervision, limited evidence-based literature, and privacy and security concerns. The biggest challenge that limits the potentials of mHealth apps is the lack of proper regulation to ensure their accuracy, quality, and performance. Governmental agencies, thirdparty companies, professional societies, and mHealth researchers must try to come up with standards and systematic methods like MARS to evaluate and certify Oral Health apps. The future strategy to be adopted in the dental health sector as regards using mobile apps may include improving the quality of dental apps using MARS criteria, maintaining cloud-based personal oral health record across health care networks, and increasing app prescription by health care providers.

\section{CONCLUSION}

Considering both objective and subjective quality scores, only two dental apps in this study scored acceptable and this situation needs immediate improvement. None of the apps scored good or excellent. Oral disease affects billions of people worldwide and mobile phone use is on the rise, and therefore the market is ripe for well-designed and effective oral health apps. As patient population becomes empowered and tech savvy, apps must be informative, entertaining, aesthetically pleasing, customizable, focusing the target group and also should be evidence based. Providing tools like mobile apps for monitoring oral health, diet and physical activity encourages fitness, lifestyle modifications and increases well-being. Therefore, it can be safely assumed that mobile apps play an increasingly important role in holistic patient care which includes preventive measures ultimately resulting in substantial reduction in health care costs.

\section{FINANCIAL SUPPORT AND SPONSORSHIP:}

Nil

\section{CONFLICTS OF INTEREST:}

There are no conflicts of interest

\section{REFERENCES}

1. García-Gómez, J. M., de la Torre-Díez, I., Vicente, J., Robles, M., López-Coronado, M., \& Rodrigues, J. J. (2014). Analysis of mobile health applications for a broad spectrum of consumers: a user experience approach. Health informatics journal, 20(1), 74-84.

2. Elgazzar, K., Aboelfotoh, M., Martin, P., \&Hassanein, H. S. (2012). Ubiquitous health monitoring using mobile web services. Procedia Computer Science, 10, 332-339.

3. Whitehead, L., \& Seaton, P. (2016). The effectiveness of self-management mobile phone and tablet apps in long-term condition management: a systematic review. Journal of medical Internet research, 18(5), e97.

4. Transformation in healthcare (https://www.pwc.com/ng/ en/assets/pdf/transformation-in-healthcare.pdf) Feb 1, 2020 . 
5. PwC. (2015). Position paper: Indian healthcare on the cusp of a digital transformation pdf https:// www. gita.org.in/Attachments/Reports/indianhealthcare-on-the-cusp-of-a-digital-transformation. pdf. Accessed: September27,2017

6. Infosys. (2015). Position paper: Digital healthcare ecosystem. At: https://www.infosys.com/ digital /white-papers/Documents/digitalhealthcareecosystem. pdf.. September27,2017

7. IQVIA Institute, Evidence and Impact on Human Health and the Healthcare SystemInstitute ReportNov 07, 2017 (https://www.iqvia.com/ insights/the-iqvia-institute/reports/the-growingvalue -of-digital-health) accessed on February 1,2020

8. Kharbanda, O. P., Wadhawan, N., Grover, A., Dhingra, K., \& Tewari, N. (2018). Oral health in India: Researchers' Perspective Part I. Journal of Pierre Fauchard Academy (India Section), 32(1-2), 6-15.

9. Underwood, B., Birdsall, J., \& Kay, E. (2015). The use of a mobile app to motivate evidence-based oral hygiene behaviour. British dental journal, 219(4), E2.

10. Aralikatte, R., Sridhara, G., Gantayat, N., \& Mani, S. (2018, January). Fault in your stars: an analysis of Android app reviews. In Proceedings of the ACM India Joint International Conference on Data Science and Management of Data (pp. 57-66). ACM.

11. Stoyanov, S. R., Hides, L., Kavanagh, D. J., \& Wilson, H. (2016). Development and validation of the user version of the Mobile Application Rating Scale (uMARS). JMIR mHealth and uHealth, 4(2), e72.

12. Kirwan, M., Duncan, M. J., Vandelanotte, C., \& Mummery, W. K. (2013). Design, development, and formative evaluation of a smartphone application for recording and monitoring physical activity levels: the 10,000 Steps "iStepLog". Health Education \& Behavior, 40(2), 140-151.

13. Stoyan R Stoyanov, Leanne Hides, David J Kavanaghet al. Mobile App Rating Scale: A New Tool for Assessing the Quality of Health Mobile Apps; JMIR MhealthUhealth. 2015 Jan-Mar; 3(1): e27

14. Tiffany, B., Blasi, P., Catz, S. L., \& McClure, J. B. (2018). Mobile apps for oral health promotion: content review and heuristic usability analysis. JMIR mHealth and uHealth, 6(9), e11432.
15. Ferretti, A., Ronchi, E., \&Vayena, E. (2019). From principles to practice: benchmarking government guidance on health apps. The Lancet Digital Health, $1(2)$, e $55-e 57$.

16. Singh, P. (2013). Orthodontic apps for smartphones. Journal of orthodontics, 40(3), 249- 255.

17. Al Musawi, A., Al Sane, M., \& Andersson, L. (2017). Smartphone App as an aid in the emergency management of avulsed teeth. Dental Traumatology, 33(1), 13-18.

18. https://www.ada.org/en/member-center/oral-healthtopics/floss. Accessed on September 2017

19. Lin, C. Y., Peng, K. L., Chen, J., Tsai, J. Y., Tseng, Y. C., Yang, J. R., \& Chen, M. H. (2014). Improvements in dental care using a new mobile app with cloud services. Journal of the Formosan Medical Association, 113(10), 742-749. 